Aswan Heart Centre (AHC), Aswan, Egypt

*Email: susykotit@hotmail.com https://doi.org/

10.21542/gcsp.2020.32

Received: 21 November 2020 Accepted: 20 December 2020 (C) 2020 The Author(s), licensee Magdi Yacoub Institute. This is an open access article distributed under the terms of the Creative Commons Attribution license CC BY-4.0, which permits unrestricted use, distribution and reproduction in any medium, provided the original work is properly cited.
Images in cardiology

\section{Thrombosis of mechanical mitral valve prosthesis during pregnancy: An ongoing "saga" in need of comprehensive solutions}

Ahmed Mahgoub, Susy Kotit*, Karim Bakry, Ahmed Magdy, Hatem Hosny, Magdi Yacoub

ABSTRACT

Emergency treatment for thrombosed mechanical valve prothesis during pregnancy is not uncommon in low- and middle-income countries. The presence of a mechanical valve continues to be an important cause of maternal morbidity and mortality. There is a pressing need for increasing awareness and feasible solutions for this huge problem. We here describe four patients who needed emergency treatment for thrombosis of mechanical valve prothesis during pregnancy and review the evolving comprehensive strategies for dealing with this issue. 


\section{INTRODUCTION}

The presence of a mechanical heart valve during pregnancy poses one of the greatest clinical challenges due to the increased risk of valve thrombosis and the impact of anticoagulation on maternal and fetal morbidity and mortality ${ }^{[1-5]}$.

Maternal cardiovascular risk is increased in the presence of a mechanical valve (WHO risk classification $\mathrm{III})^{[2,6-8]}$, and anticoagulation regimens carry an increased risk of miscarriage, hemorrhagic complications, and teratogenicity ${ }^{[9,10]}$. The chances of an eventfree pregnancy with a live birth in the presence of a mechanical prothesis is only $58 \%$ [3] and favorable outcome for mother and baby is only seen in $28 \%$ of the cases ${ }^{[11]}$.

We here describe four patients who required emergency treatment for thrombosed mitral valve prothesis, discuss complications related to mechanical valve prothesis during and after pregnancy and enumerate possible comprehensive solutions.

\section{PATIENTS AND METHODS}

Four patients presented in cardiogenic shock requiring emergency treatment for thrombosis of the mechanical valve prothesis during pregnancy.

\section{Patient 1}

A 34-year-old female was referred due to thrombosis of a mechanical mitral valve prosthesis. There was history of five normal deliveries prior to mitral valve replacement, with no significant events. After the prosthetic valve, she had unexpected pregnancy twice, despite using different contraception methods.

The first pregnancy was terminated at 28 weeks due to severe vaginal bleeding and in the $14^{\text {th }}$ week of the second pregnancy she was admitted to obstetric unit for vaginal bleeding and threatened abortion, and was shifted to unfractionated heparin. On the fourth day of admission, vaginal bleeding increased and the unfractionated heparin was stopped. Within a few days, the mechanical valve thrombosed, and she developed progressive dyspnea, followed by cardiogenic shock, requiring non-invasive CPAP and vasopressor therapy.

The patient was transferred to the Aswan Heart Centre (AHC) and went to the OR immediately. Intra-operative trans-esophageal echocardiography showed malfunctioning mitral valve prosthesis with restricted mobility of both leaflets. Excision of the thrombosed mitral prosthesis showed thrombus on both atrial (Figure 1) and ventricular sides (Figure 2) of the prosthesis. A replacement operation was successfully performed with a mechanical St. Jude $31 \mathrm{~mm}$ showing with normal flow across the valve post-operatively. Intrauterine demise of the fetus occurred intraoperative and the patient underwent surgical uterine evacuation subsequently.

\section{Patient 2}

A 32-year-old female was referred with thrombosed mechanical mitral prosthesis, resulting in cardiogenic shock. She presented at the $13^{\text {th }}$ gestational week of her pregnancy, after shifting from warfarin in the first trimester to low molecular weight heparin, which resulted in thrombosis of the valve (Figure 3 and 4). Emergency surgery was performed and the valve was replaced with a mechanical $29 \mathrm{~mm}$ prosthesis. The fetus aborted on seventh day post-operative.

\section{Patient 3}

A 29-year-old female was referred with thrombosed mechanical prosthesis (Figures 4 and 5) one-year post-operative. Patient presented on the $20^{\text {th }}$ gestational week in severe 


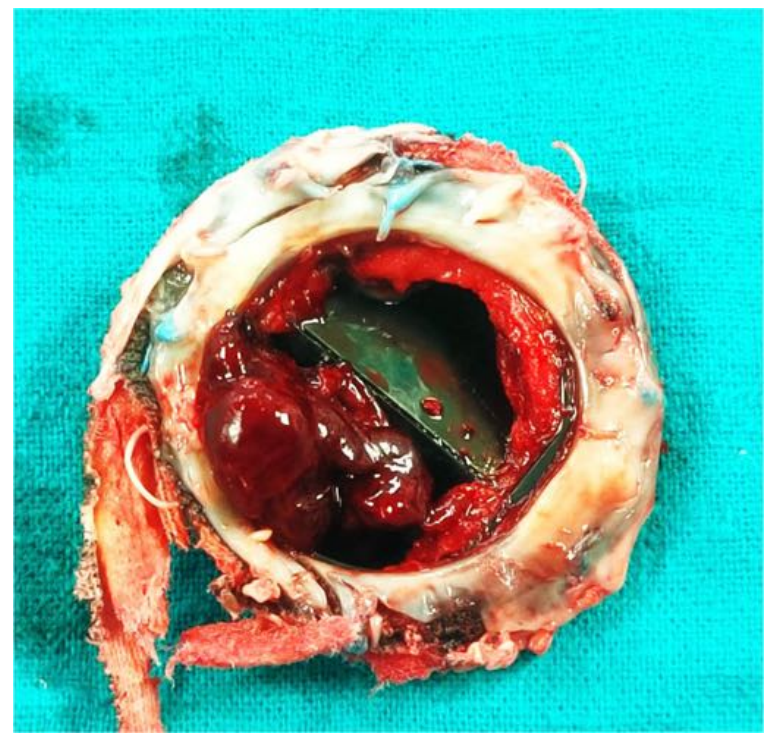

Figure 1. Mitral valve prosthesis showing large thrombus (atrial surface) in addition to large pannus.

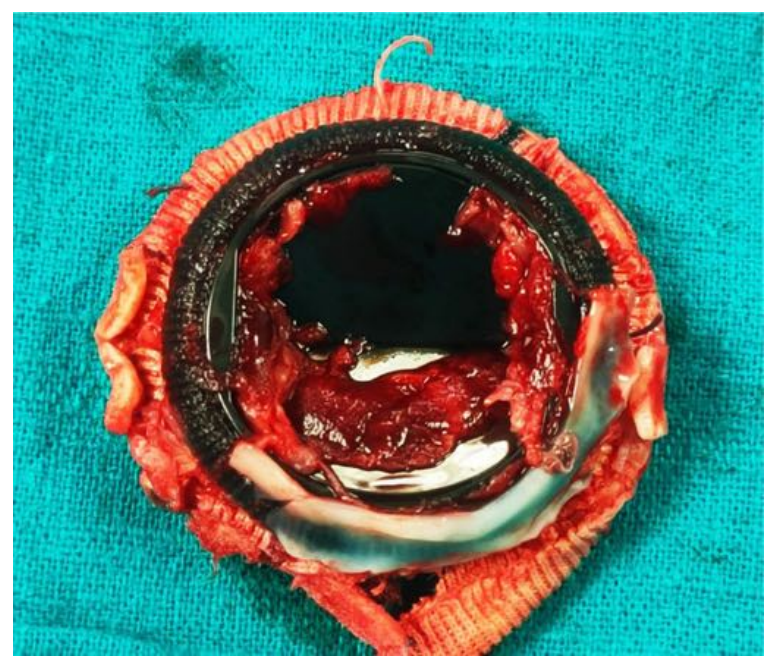

Figure 2. Mitral valve prosthesis showing large thrombus (ventricular surface).

cardiogenic shock, requiring ventilation and vasopressor therapy while on a fixed dose of warfarin ( $5 \mathrm{mg}$ daily). Fetal death was diagnosed at the time of presentation. Emergency mitral valve replacement was performed, and the patient was discharged to the ICU on high inotropic support. Persistent shock did not resolve and the patient died a few hours post-operative.

\section{Patient 4}

A 28-year-old lady presented with thrombosed mechanical prosthesis five years postoperative (Figure 6). There was history of two previous abortions since the cardiac procedure. Patient presented with cardiogenic shock on the $15^{\text {th }}$ gestational week and while compliant to warfarin and within target INR. Emergency valve replacement with biological valve was performed (Figure 7). Patient was discharged from hospital with 


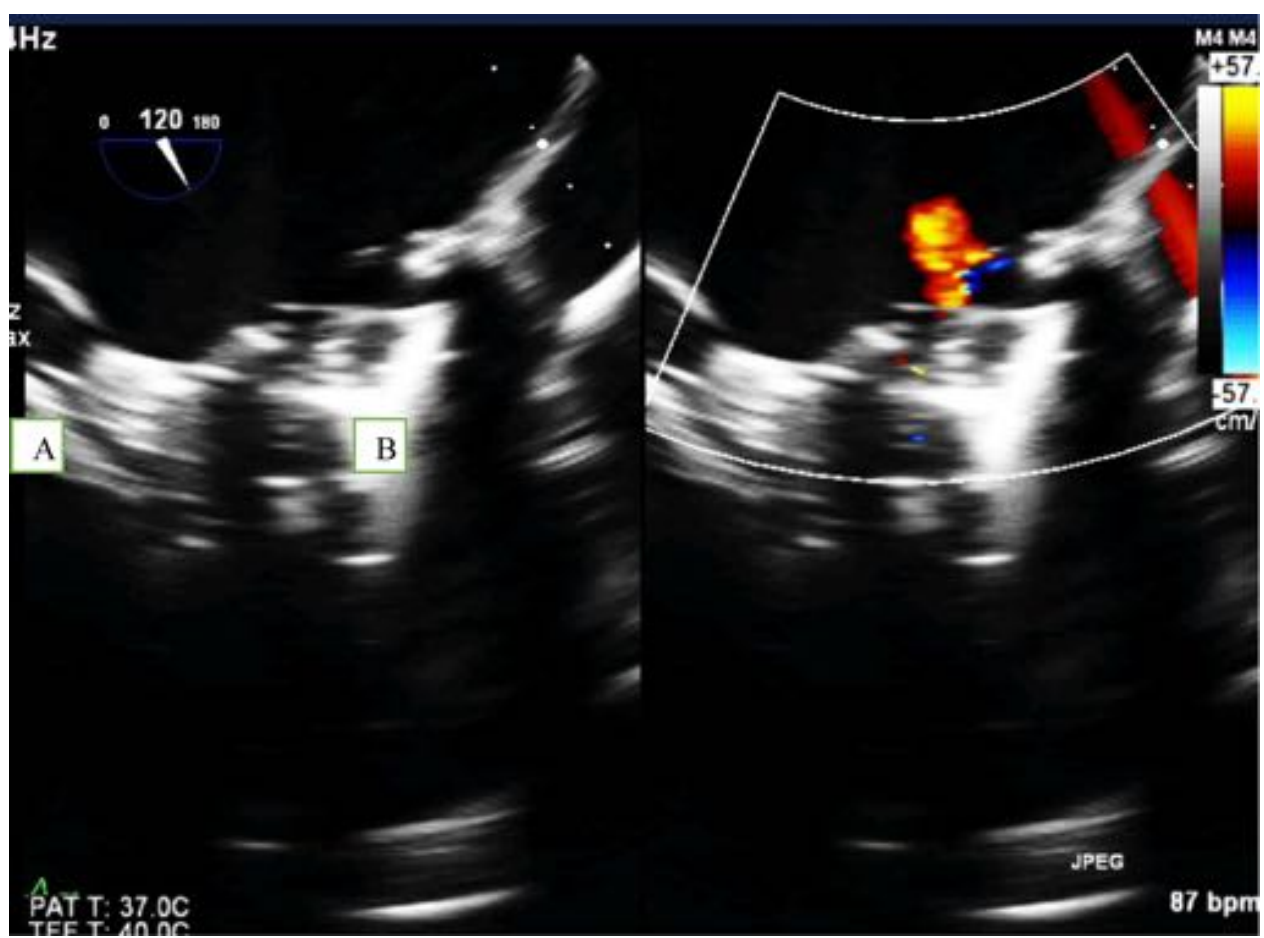

Figure 3. Trans-esophageal echo, mid-esophageal view, angle $120^{\circ}$ showing thrombus attached to the mitral prosthesis leaflet (A) and washing jet across obstructed valve (B).

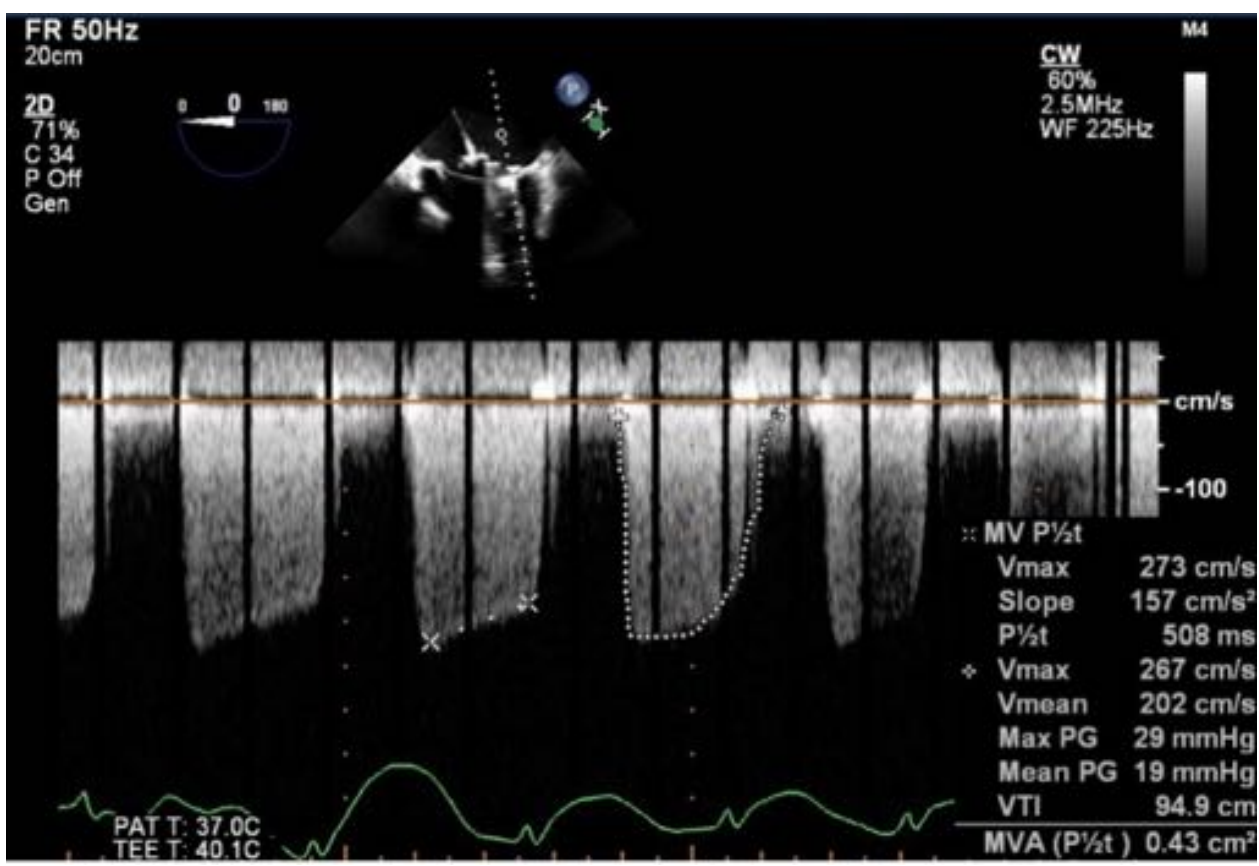

Figure 4. Continuous wave Doppler showing increased gradients across MV (pre-operative). 


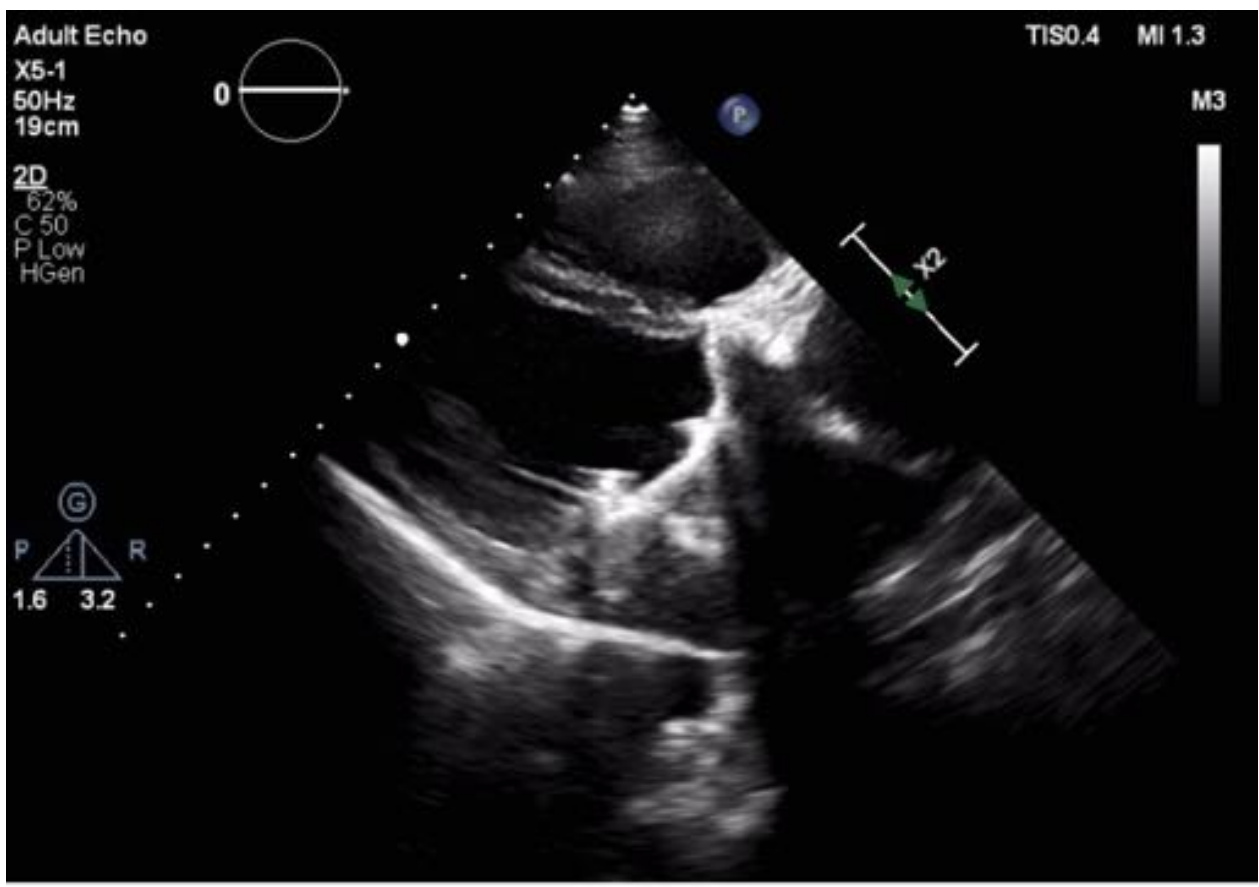

Figure 5. Trans-thoracic echo showing malfunctioning mitral prosthesis.

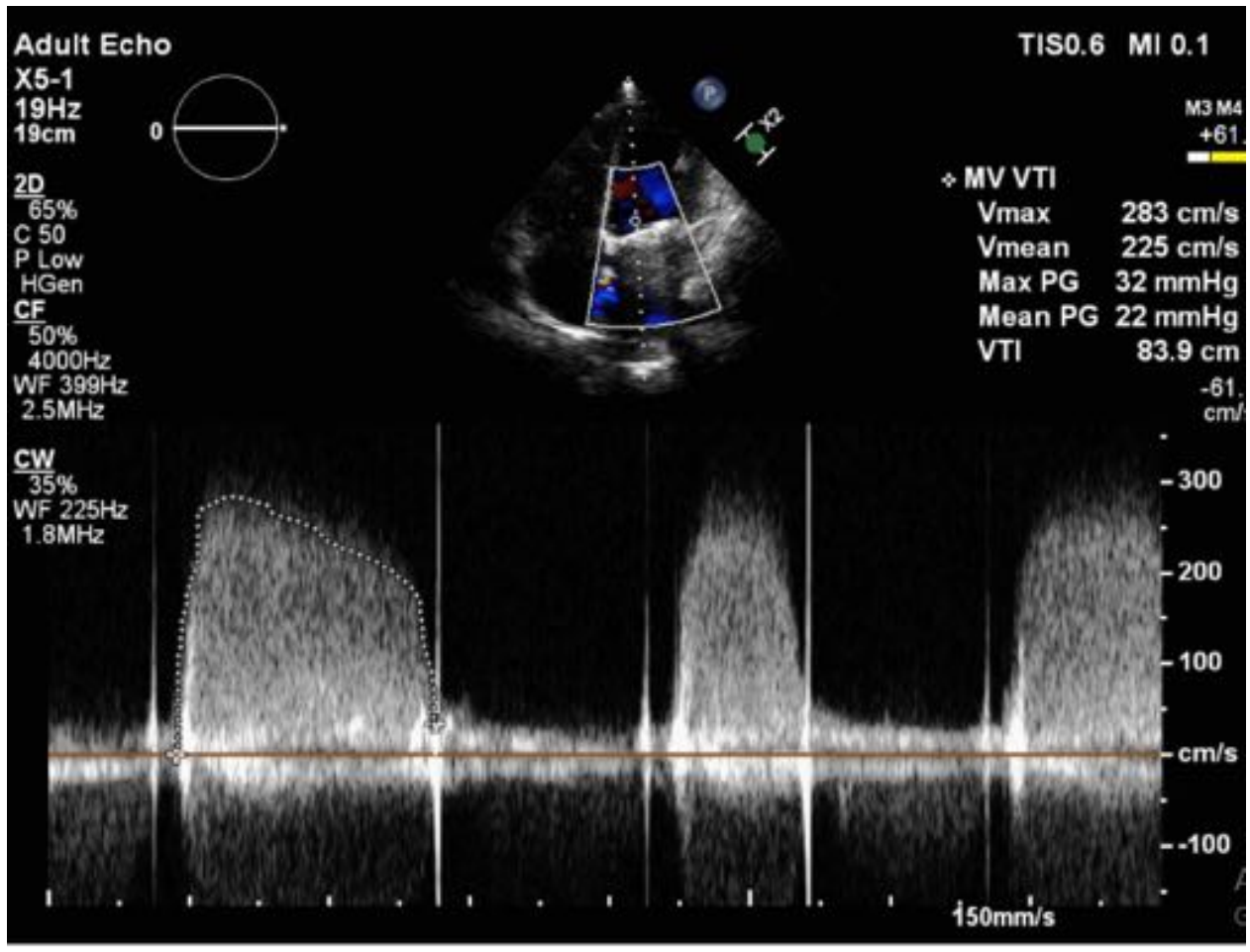

Figure 6. Continuous wave Doppler showing increased gradients across MV (pre-operative).

viable fetus. Unfortunately, during the $28^{\text {th }}$ gestational week, abortion was performed due to an attack of massive vaginal bleeding.

\section{Maternal morbidity and mortality in relation to mechanical valve prothesis}

Due to an increase in successfully corrected congenital heart disease (CHD) and the continuous presence of rheumatic heart disease (RHD), a significant number of women 


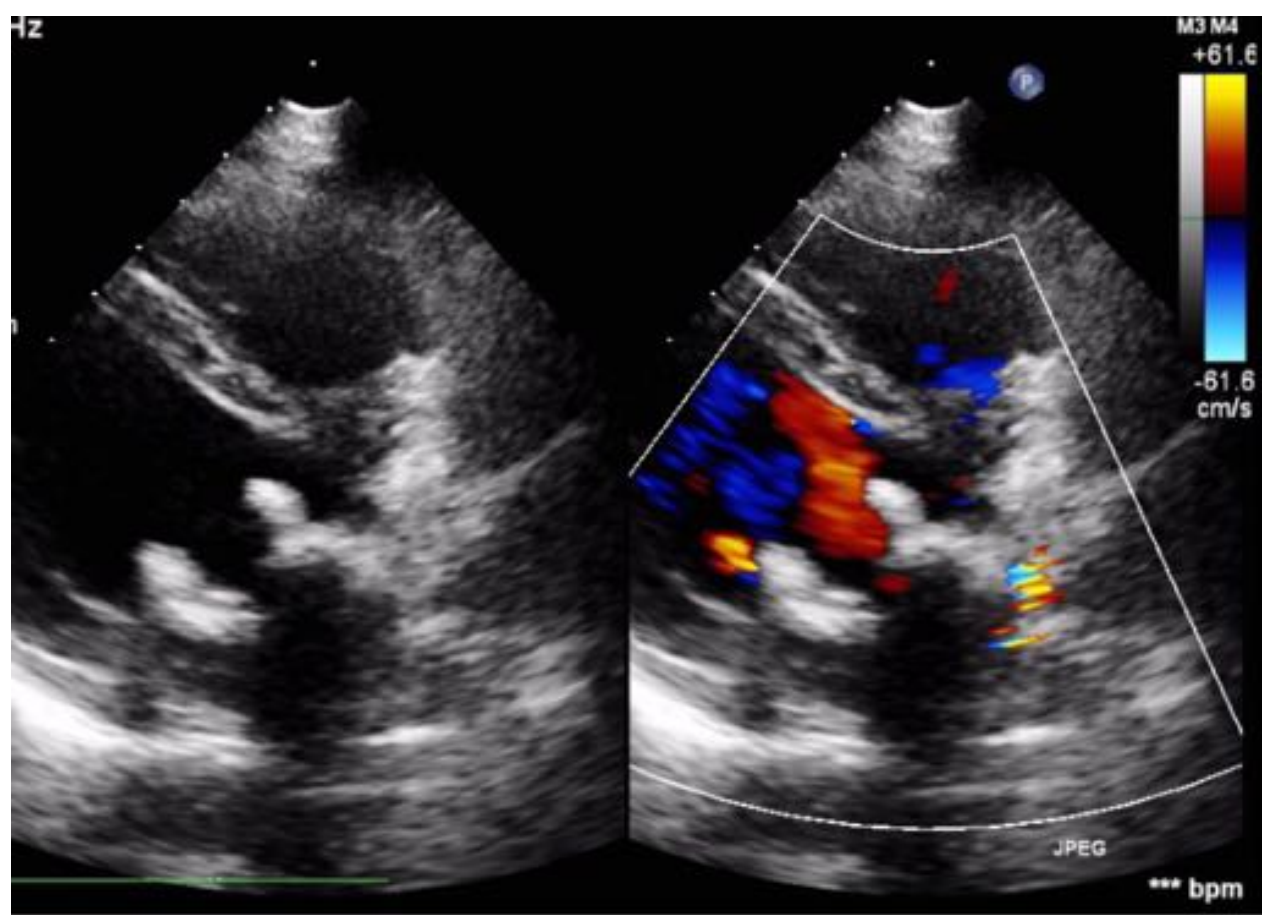

Figure 7. Mitral valve bioprothesis with normal flow across.

with prosthetic valves are of childbearing age, in whom maternal and fetal morbidity and mortality risks are increased. In non-western countries, rheumatic valvular disease represents up to $89 \%$ of all cardiovascular diseases in pregnancy ${ }^{[12-15]}$.

Pregnant women with prosthetic heart valves, particularly of the mechanical type, are especially at high risk for adverse outcomes ${ }^{[1,16-22]}$.

The presence of a mechanical valve (WHO risk classification III) is a predictor of maternal cardiovascular and neonatal events ${ }^{[2,6-8]}$, and anticoagulation regimens carry an increased risk of miscarriage, hemorrhagic complications and teratogenicity $[9,10]$. Women with prosthetic heart valves are more likely to experience severe maternal morbidity, (more than 9 times higher than matched women without heart disease), with a nonfatal event occurring in $10 \%$ of pregnancies, which is at least a 7 -fold increase compared with pregnancies in matched controls ${ }^{[22]}$. Valve thrombosis and hemorrhagic complications occur in $4.7 \%$ and $23.1 \%{ }^{[3]}$, respectively. Maternal mortality in the presence of mechanical heart valves is up to $4 \%^{[23]}$.

The chances of an event-free pregnancy with a live birth in the presence of a mechanical prothesis is only $58 \%{ }^{[3]}$ and favorable outcomes for mother and baby are only seen in $28 \%$ of cases $^{[11]}$.

Maternal adverse outcomes in the presence of a prosthetic heart valve include thromboembolic events, valve thrombosis, cardiovascular compromise, arrythmia, infective endocarditis, obstetric hemorrhage, and maternal mortality ${ }^{[9,10,21]}$ which is usually related to valve thrombosis ${ }^{[24]}$.

The fetus is at risk for small gestational age, low birth weight, congenital malformation with the use of anticoagulants, pre-term birth, miscarriage and perinatal mortality including neonatal mortality and stillbirth ${ }^{\left[21,24^{-28]}\right.}$.

Mechanical valve thrombosis is a life-threatening situation, and in pregnancy there are no clear treatment options or management in order to lower the risk both for the mother as well as the fetus. 


\section{Prosthetic heart valves}

Due to RHD and congenital heart disease a significant number of patients with valvular heart disease, requiring prosthetic valves, are of childbearing age. The diseased native valve can be replaced by a mechanical or bioprosthetic valve, both carrying significant risks and complications. Therefore, care for women with mechanical heart valves in pregnancy poses one of the greatest clinical challenges ${ }^{[3,29]}$.

Mechanical valve prosthesis is both a cure for a serious disorder as well as a disease itself as it requires lifelong anticoagulation with strict monitoring to protect against thrombo-embolic events. Although, even with the right care, the annual risk for these events remains at around $1^{[29]}$, not to mention the associated risks of bleeding. Importantly, thrombotic risk increases during pregnancy due to the associated pro-thrombotic state, raising the annual risk to $4 \%{ }^{[8]}$.

Mechanical valves show a higher complication rate for both maternal and fetal events compared to bio-protheses ${ }^{[3,30]}$. The risk decreases from $42 \%$ to $22 \%$ in the presence of a bioprosthetic valve instead of a mechanical valve ${ }^{[31]}$. Uncomplicated pregnancies are often seen in patients with well-functioning bioprosthetic heart valves and the absence of other cardiac risk factors due to the fact that they are less thrombogenic than mechanical valves ${ }^{[9,10]}$. However, the main issue with bioprosthetic valves is their finite lifespan and their risk of structural valvular deterioration (SVD) which can require reoperation in about $50 \%$ of women of childbearing age within 10 years of the initial operation $^{[26]}$. Importantly, pregnancy might also accelerate SVD and reoperation might be required during pregnancy and in the early postpartum period $[9,10,26,32]$.

Importantly, all patients with prosthetic heart valves (bioprosthetic or mechanical) are at risk of endocarditis ${ }^{[33,34]}$.

Apart from maternal adverse events and fetal demise in women with cardiac disease, the need for cardiac interventions post-partum was shown to be increased. This can be in the form of ICD and PPM implantation, valve replacement due to the hemodynamic effects of pregnancy on certain valvular lesions, up to LVAD implantation and heart transplantation, which urges the need for continued cardiovascular care in the postpartum period and beyond ${ }^{[35]}$.

\section{Anticoagulation}

Causes for pregnancy related adverse events in women with prosthetic heart valves are partly attributed to the increased cardiac output during pregnancy and its effect on valve function, alongside the state of increased coagulability leading to the added risk of mechanical valve thrombosis ${ }^{[11,16,17,20,36]}$. The elevation in circulating pro-coagulant factors and maternal hormones lead to a decrease in prothrombin time, activated partial thromboplastin time, thrombin time and international normalized ratio (INR) ${ }^{[37,38]}$. Therefore, adequate anticoagulation is more difficult to achieve during pregnancy, increasing the risk of thromboembolic events and mechanical valve thrombosis.

It is also important to take into account the devastating effects of anticoagulation during pregnancy as warfarin is teratogenic and heparin is less effective in preventing thrombotic events compared to warfarin. The risk of thromboembolic events during pregnancy in patients treated with heparin is approximately $10 \%[9,39]$, compared with the $3.9 \%$ risk with warfarin use throughout pregnancy ${ }^{[24,40]}$. Furthermore, the use of unfractionated heparin during pregnancy can be problematic, with an attenuated response of activated partial thromboplastin time (aPT) and failure to achieve appropriate aPTT levels, variable sensitivities of aPTT reagents, and wide peaks or troughs with the use of subcutaneous unfractionated heparin ${ }^{[39]}$. The use of warfarin 
between 6 and 12 weeks' gestational age results in a 6\% to 10\% risk of embryopathy and fetal malformations ${ }^{[41,42]}$; increases the risk for maternal hemorrhage and fetal hemorrhage as it crosses the placenta and shows higher rates of fetal loss ${ }^{[2,24]}$. Furthermore, the benefits of lowering the daily doses to less than $5 \mathrm{mg} /$ day to decrease risks of embryopathy ${ }^{[29]}$ remains unconfirmed ${ }^{[1]}$. Currently, there is no indication for the use of novel oral anticoagulants (NOACs) for mechanical heart valves as the data presented suggests increased bleeding as well as thrombotic events ${ }^{[43]}$ and there is no data on their risk during pregnancy.

Pregnant patients who suffer a thrombotic or bleeding event while on appropriate anticoagulation therapy are a dilemma as there are no clear options for treatment and surgical interventions are not recommended unless as a last resort. Therefore, the use of thrombolytic drugs such as streptokinase is recommended (for up to 72 hours) in order to solve thrombosis during pregnancy. However, there is limited data available on the success rates of this method and surgery remains generally inevitable if thrombolysis fails. On the other hand, bleeding has no other treatment except discontinuation of the anticoagulant drug or shifting to a less effective agent and accept the risk of thrombosis.

In conclusion, there are no clear guidelines or reliable data from randomized trials for the management of anticoagulation or even its complications during pregnancy. Also, there is no data on how long serum levels for coagulation factors remain increased, which might be a risk for prosthetic valve thrombosis in the period after childbirth. It is also unclear when to restart anticoagulation regimen after childbirth, keeping in mind the risk of bleeding and gynecology complications and valve thrombosis. All of this raises the question whether we should encourage the use of biological valves or the liberal use of mitral valve repair in young females, accepting the risk of re-operation.

\section{Alternative techniques}

Bioprosthetic valves have shown less maternal and fetal risks. However, in order for bioprosthetic valves to be considered for young patients, the morbidity and mortality associated with mechanical valves would need to outweigh the accumulated mortality and inconvenience of re-interventions for bioprosthetic valves. Several Western studies did conclude that there was no difference in long-term mortality between mechanical and tissue valves ${ }^{\left[44^{-51]}\right.}$ however, the benefits might be much more prominent in LMIC's where availability of anticoagulation and medical services might have an impact on clinical outcomes.

In experienced hands, mitral valve repair has shown favorable outcomes, especially in rheumatic heart disease, which is the main reason for valve pathology in the young, and should be considered as the first option for young females.

Hopefully, in the near future, tissue engineered valves (TEHV) may overcome deficiencies of currently available heart valve substitutes. There are approaches being contemplated to generate a living, functional, and durable heart valve structure which could be a potential solution to the shortcomings of the existing mechanical and bioprosthetic valves ${ }^{[52,53]}$.

\section{Contraception in the presence of a mechanical heart valve}

Pregnancy in women with heart disease is a risky event. Therefore, the choice of contraception requires consideration of pregnancy risk, available contraception options as well as their risks and benefits, failure rates, understanding the consequences of unplanned pregnancy, and the patient's preferences.

Due to the potential for thromboembolic complications and valve thrombosis, combined hormonal contraceptives in the form of pills, transdermal patches or vaginal 
rings are not recommended in women with mechanical heart valves ${ }^{[54,55]}$. In women at prohibitively high risk for pregnancy, permanent forms of contraception can be considered.

Importantly, there is scarce data on contraception for women with heart disease in general and especially those with mechanical prostheses. As a result, physicians may be too cautious and deny contraception, while not being aware of the range of effectivity and safety of various contraceptive methods, leading to the use of less appropriate strategies resulting in unexpected pregnancies and complications of the underlying cardiac disease ${ }^{[56]}$.

\section{Possible solutions and future directions}

Avoidable deaths from pregnancy related causes, especially due to thrombosis of mechanical heart valves, occur daily on a global scale. Importantly, heart disease is expected to become even a greater contributor to maternal mortality worldwide due to improved survival of women with congenital heart disease and RHD. This results in a significant number of women with prosthetic valves being of childbearing age, in whom maternal and fetal morbidity and mortality risks are increased, due to pregnancy related pro-thrombotic state as well as the dilemma of anticoagulation for mechanical prosthetic valves. Conventional anticoagulation results in significant maternal and fetal morbidity and mortality while heparin is less effective in preventing thrombotic events compared to warfarin.

In the case of thrombosis of the prosthetic valve, the options are limited to streptokinase and surgery in case thrombolysis fails. The maternal and fetal risks of peripartum cardiac surgery cannot be ignored. Our patient series illustrates the dilemma and the risks and outcomes of such procedures. In case of bleeding due to anticoagulation the only treatment option is discontinuation of the anticoagulant drug or shifting to a less effective agent and accept the risk of thrombosis.

The presence of a mechanical heart valve during pregnancy poses therefore one of the greatest clinical challenges for which there are no clear guidelines or reliable clinical data to lean on. Insights on management of women with cardiac disease in the presence of prosthetic valves and the use of anticoagulation are urgently needed.

Bio-protheses show more favorable results regarding pregnancies with less complications, which raises a question whether we should encourage the use of biological valves in young females. However, their finite lifespan and risk of structural valvular deterioration (SVD) leading to reoperation is a concern. Clinical data should analyze the benefits of biological valves during pregnancy as these benefits might be much more prominent in LMIC's where availability of anticoagulation and medical care is limited.

Mitral valve repair might be a good alternative as it has shown favorable outcomes and should be considered as the first option in young females, accepting the risk of re-operation.

Mothers with heart disease need special care before, during and after pregnancy. Management of women with prosthetic heart valves is required throughout pregnancy and after childbirth in a specialized program for high-risk patients by a multidisciplinary team consisting of an obstetrician, family physician and cardiologist. This multidisciplinary approach should address counselling, medical management, guidance for anticoagulation during pregnancy, protection of the fetus, and importantly, family planning in the future.

This shows the need for specialized maternity clinics for women with prosthetic heart valves in order to improve the quality of care and improve outcomes especially in 
developing countries where medical care is scarce ${ }^{[59]}$ and prevention and management will have a huge impact on the overall outcomes.

\section{CONCLUSIONS}

This small series of patients serves to illustrate the tip of the iceberg in the dilemma of the combination of mechanical prothesis and pregnancy, which justifies the subtitle of this article "An ongoing "saga" in need of comprehensive solutions.

Thrombosis of mechanical valve prosthesis during pregnancy is still a major problem that carries significant risk of morbidity and mortality. The decision of anticoagulation regimen in pregnancy has to weigh risks of thrombotic events and bleeding versus fetal and maternal safety. The presence of a mechanical heart valve during pregnancy poses therefore one of the greatest clinical challenges for which there are no clear guidelines or reliable clinical data. Insights on management of pregnant women with the combination of prosthetic valves and anticoagulation are urgently needed.

Valve repair, or the use of bio-protheses, show favorable results regarding pregnancies - which raises the question whether we should encourage these alternatives in young females, accepting the risk of re-operation. The maternal benefits for both options should be studied in depth. Contraception, risks of pregnancy, and family planning should be discussed with all patients.

Mothers with heart disease need special care before, during and after pregnancy. Multidisciplinary follow-up in dedicated clinics might lead to a significant reduction in peripartum complications and post-partum mortality. Implementation of these clinics should be encouraged in order to prevent cardiovascular events during pregnancy and beyond.

\section{REFERENCES}

[1] D’Souza R, Ostro J, Shah PS, et al. Anticoagulation for pregnant women with mechanical heart valves: A systematic review andmeta-Analysis. Eur Heart J. 2017;38(19):1509-1516 doi: 10.1093/eurheartj/ehx032.

[2] Elkayam U, Singh H, Irani A, Akhter MW. Anticoagulation in pregnant women with prosthetic heart valves. J Cardiovasc Pharmacol Ther. 2004;9(2):107-115 doi: 10.1177/107424840400900206.

[3] Van Hagen IM, Roos-Hesselink JW, Ruys TPE, et al. Pregnancy in women with a mechanical heart valve. Circulation. 2015;132(2):132-142 doi: 10.1161/CIRCULATIONAHA.115.015242.

[4] Khanom M. cardiology AH of indian college of, 2015 undefined. Valvular heart disease in pregnancy: A review. Elsevier. https://www.sciencedirect.com/science/article/pii/S1561881115000978 (Accessed 8 November 2020).

[5] Chan WS, Anand S, Ginsberg JS. Anticoagulation of pregnant women with mechanical heart valves: A systematic review of the literature. Arch Intern Med. 2000;160(2):191-196 doi: 10.1001/archinte.160.2.191.

[6] Regitz-Zagrosek V, Blomstrom Lundqvist C, Borghi C, et al. ESC Guidelines on the management of cardiovascular diseases during pregnancy. Eur Heart J. 2011;32(24):3147-3197 doi: 10.1093/eurheartj/ehr218.

[7] Silversides CK, Grewal J, Mason J, et al. Pregnancy outcomes in women with heart disease: The CARPREG II Study. J Am Coll Cardiol. 2018;71(21):2419-2430 doi: 10.1016/j.jacc.2018.02.076.

[8] Thorne S, Nelson-Piercy C, MacGregor A, et al. Pregnancy and contraception in heart disease and pulmonary arterial hypertension. J Fam Plann Reprod Heal Care. 2006;32(2):75-81.

[9] Sbarouni EOC. Outcome of pregnancy in women with valve prostheses. Br Heart J. 1994;71(2):196-201 https://www.google.com/search?q=Sbarouni+E\%2C+Oakley+C.+Outcome+of+pregnancy+in+ women+with+valve+prostheses.+Br+Heart+J.+1994\%3B71(2)\%3A196--201. $\{\&\} r l z=1 C_{1} C H N Y$ enEG871EG871\{\&\}oq=Sbarouni+E\%2C+Oakley+C.+Outcome+of+pregnancy+in+women+with+valve+ prostheses. $+\mathrm{Br}+\mathrm{He}$ (Accessed 2 November 2020).

[10] Sadler L, McCowan L, White H, Stewart A, Bracken M, North R. Pregnancy outcomes and cardiac complications in women with mechanical, bioprosthetic and homograft valves. BJOG An Int J Obstet Gynaecol. 2000;107(2):245-253 doi: 10.1111/j.1471-0528.2000.tb11696.x.

[11] Vause S, Clarke B, Tower CL, Hay CRM, Knight M. Pregnancy outcomes in women with mechanical prosthetic heart valves: a prospective descriptive population based study using the United Kingdom 
Obstetric Surveillance System (UKOSS) data collection system. BJOG An Int J Obstet Gynaecol. 2017;124(9):1411-1419 doi: 10.1111/1471-0528.14478.

[12] Siu SC, Sermer M, Colman JM, et al. Prospective multicenter study of pregnancy outcomes in women with heart disease. Circulation. 2001;104(5):515-521 doi: 10.1161/hc3001.093437.

[13] Stangl V, Schad J, Gossing G, Borges A, Baumann G, Stangl K. Maternal heart disease and pregnancy outcome: A single-centre experience. Eur J Heart Fail. 2008;10(9):855-860 doi: 10.1016/j.ejheart.2008.07.017.

[14] Watkins DA, Sebitloane M, Engel ME, Mayosi BM. The burden of antenatal heart disease in South Africa: A systematic review. BMC Cardiovasc Disord. 2012;12 doi: 10.1186/1471-2261-12-23.

[15] Diao M, Kane A, Ndiaye MB, et al. Pregnancy in women with heart disease in sub-Saharan Africa la grossesse des femmes atteintes de cardiopathie en Afrique subsaharienne. Arch Cardiovasc Dis. 2011;104(6-7):370-374 doi: 10.1016/j.acvd.2011.04.001.

[16] Alshawabkeh L, Economy KE, Valente AM. Anticoagulation during pregnancy: evolving strategies with a focus on mechanical valves. J Am Coll Cardiol. 2016;68(16):1804-1813 doi: 10.1016/j.jacc.2016.06.076.

[17] D'Souza R, Silversides CK, McLintock C. Optimal anticoagulation for pregnant women with mechanical heart valves. Semin Thromb Hemost. 2016;42(7):798-804 doi: 10.1055/s-0036-1593418.

[18] Elkayam U, Gol S, Pieper PG, Silverside CK. High-risk cardiac disease in pregnancy: part I. J Am Coll Cardiol. 2016;68(4):396-410 doi: 10.1016/j.jacc.2016.05.048.

[19] Elkayam U, Gol S, Pieper PG, Silverside CK. High-risk cardiac disease in pregnancy: Part II. J Am Coll Cardiol. 2016;68(5):502-516 doi: 10.1016/j.jacc.2016.05.050.

[20] Steinberg ZL, Dominguez-Islas CP, Otto CM, Stout KK, Krieger EV. Maternal and fetal outcomes of anticoagulation in pregnant women with mechanical heart valves. J Am Coll Cardiol. 2017;69(22):2681-2691 doi: 10.1016/j.jacc.2017.03.605.

[21] Lawley CM, Algert CS, Ford JB, Nippita TA, Figtree GA, Roberts CL. Heart valve prostheses in pregnancy: Outcomes for women and their infants. J Am Heart AsSOC. 2014;3(3) doi: 10.1161/JAHA.114.000953.

[22] Siu SC, Lam M, Le B, Garg P, Silversides CK, Ray JG. Morbidity in pregnant women with a prosthetic heart valve. Am J Obstet Gynecol MFM. 2020;2(3):100105 doi: 10.1016/j.ajogmf.2020.100105.

[23] Shannon MS, Edwards MB, Long F, Taylor KM, Bagger JP, De Swiet M. Anticoagulant Management of pregnancy following heart valve replacement in the United Kingdom, 1986-2002. J Heart Valve Dis. 2008;17(5):526-532 https://europepmc.org/article/med/18980086 (Accessed 30 November 2020).

[24] Chan WS, An S, Ginsberg JS. Anticoagulation of pregnant women with mechanical heart valves: A systematic review of the literature. Arch Intern Med. 2000;160(2):191-196 doi: 10.1001/archinte.160.2.191.

[25] Schaefer C, Hannemann D, Meister R, et al. Vitamin K antagonists and pregnancy outcome. A multi-centre prospective study. Thromb Haemost. 2006;95(6):949-957 doi: 10.1160/THo6-02-0108.

[26] Elkayam U, Bitar F. Valvular heart disease and pregnancy - Part II: Prosthetic valves. J Am Coll Cardiol. 2005;46(3):403-410 doi: 10.1016/j.jacc.2005.02.087.

[27] Oran B, Lee-Parritz A, Ansell J. Low molecular weight heparin for the prophylaxis of thromboembolism in women with prosthetic mechanical heart valves during pregnancy. Thromb Haemost. 2004;92(4):747-751 doi: 10.1160/THo4-06-0337.

[28] McLintock C, McCowan LME, North RA. Maternal complications and pregnancy outcome in women with mechanical prosthetic heart valves treated with enoxaparin. BJOG An Int J Obstet Gynaecol. 2009;116(12):1585-1592 doi: 10.1111/j.1471-0528.2009.02299.X.

[29] Nishimura RA, Otto CM, Bonow RO, Carabello BA, Erwin JP, Guyton RA, O'Gara PT, Ruiz CE, Skubas NJ, Sorajja P, Sundt TMTJ. 2014 AHA/ACC guideline for the management of patients with valvular heart disease: a report of the American College of Cardiology/American Heart Association Task Force on Practice Guidelines. Circ. 2014;129e521-e643.

[30] McLintock C. Anticoagulant therapy in pregnant women with mechanical prosthetic heart valves: no easy option. Thromb Res. 2011;127(3):S56-S60.

[31] Van Hagen IM, Roos-Hesselink JW, Ruys TPE, et al. Pregnancy in women with a mechanical heart valve. Circulation. 2015;132(2):132-142 doi: 10.1161/CIRCULATIONAHA.115.015242.

[32] Badduke BR, Jamieson WR, Miyagishima RT, Munro Al, Gerein AN, MacNab J, et al. Pregnancy and childbearing in a population with biological valvular prostheses. J Thorac Cardiovasc Surg. 1991;102(2):179-86.

[33] Maternal endocarditis SG. In: Steer PJ, Gatzoulis MA, Bak P, eds. Hear Dis pregnancy London. UK RCOG Press,2006:267-82.

[34] Wilson W, Taubert KA, Gewitz M, et al. Prevention of infective endocarditis: guidelines from the American Heart Association: a guideline from the American Heart Association Rheumatic Fever, Endocarditis and Kawasaki Disease Committee, Council on Cardiovascular Disease in the Young, and the Council on Clinical Cardiology, Council on Cardiovascular Surgery and Anesthesia, and the Quality of Care and Outcomes Research Interdisciplinary Working Group. J Am Dent Assoc. 2008;139(Suppl 15):3S-24S doi: 10.1161/CIRCULATIONAHA.106.183095.

[35] Magun E, DeFilippis EM, Noble S, et al. Cardiovascular care for pregnant women with cardiovascular disease. J Am Coll Cardiol. 2020;76(18):2102-2113 doi: 10.1016/j.jacc.2020.08.071.

[36] Elkayam U. Anticoagulation therapy for pregnant women with mechanical prosthetic heart valves: how to improve safety? J Am Coll Cardiol. 2017;69(22):2692-2695 doi: 10.1016/j.jacc.2017.04.034.

[37] Bremme KA. Haemostatic changes in pregnancy. Best Pract Res Clin Haematol. 2003;16(2):153-168 doi: 10.1016/S1521-6926(03)00021-5. 
[38] Hui C, Lili M, Libin C, et al. Changes in coagulation and hemodynamics during pregnancy: A prospective longitudinal study of 58 cases. Arch Gynecol Obstet. 2012;285(5):1231-1236 doi: 10.1007/s00404-0112137-x.

[39] Warnes CA. Prosthetic heart valves.

[40] Maxwell CV, Poppas A, Dunn ESM. Pregnancy, mechanical heart valves and anticoagulation: navigating the complexities of management during gestation. In: Rosene-Montella K, Keely EJ, Barbour LA, Lee RV, eds. Med care pregnant patient 2 Philadelphia, PA Am Coll Physicians.2007:344-55.

[41] H JG. Embryopathy associated with oral anticoagulant therapy. Birth Defects. 1965;12:133-140.

[42] Shaul WL, Emery H, Hall JG. Chondrodysplasia Punctata and Maternal Warfarin Use During Pregnancy. Am J Dis Child. 1975;129(3):360-362 doi: 10.1001/archpedi.1975.02120400060014.

[43] Shazly A, Afifi A. RE-ALIGN: first trial of novel oral anticoagulant in patients with mechanical heart valves-the search continues. Glob Cardiol Sci Pract. 2014;2014(1):88-89.

[44] Schnittman SR, Adams DH, Itagaki S, Toyoda N, Egorova NN, Chikwe J. Bioprosthetic aortic valve replacement: Revisiting prosthesis choice in patients younger than 50 years old. J Thorac Cardiovasc Surg. 2018;155(2):539-547.e9 doi: 10.1016/j.jtcvs.2017.08.121.

[45] Lund O, Bland M. Risk-corrected impact of mechanical versus bioprosthetic valves on longterm mortality after aortic valve replacement. J Thorac Cardiovasc Surg. 2006;132(1) doi: 10.1016/j.jtcvs.2006.01.043.

[46] Wang Y, Chen S, Shi J, Li G, Dong N. Mid-to long-term outcome comparison of the Medtronic Hancock II and bi-leaflet mechanical aortic valve replacement in patients younger than 60 years of age: $\mathrm{A}$ propensity-matched analysis. Interact Cardiovasc Thorac Surg. 2016;22(3):280-286 doi: 10.1093/icvts/ivv347.

[47] Stassano P, Di Tommaso L, Monaco M, et al. Aortic valve replacement. A prospective randomized evaluation of mechanical versus biological valves in patients ages 55 to 70 years. J Am Coll Cardiol. 2009;54(20):1862-1868 doi: 10.1016/j.jacc.2009.07.032.

[48] Hirji SA, Kolkailah AA, Ramirez-Del Val F, et al. Mechanical versus bioprosthetic aortic valve replacement in patients aged 50 years and younger. Ann Thorac Surg. 2018;106(4):1113-1120 doi: 10.1016/j.athoracsur.2018.05.073.

[49] Minakata K, Tanaka S, Tamura N, et al. Comparison of the long-term outcomes of mechanical and bioprosthetic aortic valves: A propensity score analysis. Circ J. 2017;81(8):1198-1206 doi: 10.1253/circj.CJ-17-0154.

[50] Goldstone AB, Chiu P, Baiocchi M, et al. Mechanical or biologic prostheses for aortic-valve and mitralvalve replacement. N Engl J Med. 2017;377(19):1847-1857 doi: 10.1056/nejmoa1613792.

[51] Tsvelodub S, Pieper B, Stock S, Sievers HHRD. Long-Term (up to 21 Years) follow up after biological and mechanical aortic valve replacement in younger patients. J Hear Valve Dis. 2017;26(5):528-536 PMID 29762921.

[52] Zhang BL, Bianco RW, Schoen FJ. Preclinical assessment of cardiac valve substitutes: Current status and considerations for engineered tissue heart valves. Front Cardiovasc Med. 2019;6(June):1-9 doi: $10.3389 /$ fcvm.2019.00072.

[53] Schoen FJ. Heart valve tissue engineering: Quo vadis? Curr Opin Biotechnol. 2011;22(5):698-705 doi: 10.1016/j.copbio.2011.01.004.

[54] Nanna M, Stergiopoulos K. Pregnancy complicated by valvular heart disease: an update doi: 10.1161/JAHA.113.000712.

[55] Thorne S, MacGregor A, Nelson-Piercy C. Risk of contraception and pregnancy in heart disease. Heart. 2006;92(10):1520-1525 doi: 10.1136/hrt.2006.095240.

[56] Regitz-Zagrosek V, Blomstrom Lundqvist C, Borghi C, et al. ESC Guidelines on the management of cardiovascular diseases during pregnancy. Eur Heart J. 2011;32(24):3147-3197 doi: 10.1093/eurheartj/ehr218.

[57] Sliwa K, Azibani F, Baard J, et al. Reducing late maternal death due to cardiovascular disease - A pragmatic pilot study. Int J Cardiol. 2018;272:70-76 doi: 10.1016/j.ijcard.2018.07.140.

[58] Ouyang P, Sharma G. The potential for pregnancy heart teams to reduce maternal mortality in women with cardiovascular disease. J Am Coll Cardiol. 2020;76(18):2114-2116 doi: 10.1016/j.jacc.2020.09.007.

[59] WHO. 2019. Trends in maternal mortality: 2000 to 2017: estimates by WHO, UNICEF, UNFPA, World Bank Group and the United Nations Population Division. Geneva: World Health Organization. WHO 2019. 